\title{
Glucagon-like Peptide 2 Improves Nutrient Absorption and Nutritional Status in Short-Bowel Patients With No Colon
}

\author{
PALLE BEKKER JEPPESEN,* BOLETTE HARTMANN, ${ }^{\ddagger}$ JESPER THULESEN, $§$ JESPER GRAFF,\| \\ JETTE LOHMANN, " BIRTHE STENB/EK HANSEN,* FLEMMING TOFTENG,* STEEN SEIER POULSEN,\$ \\ JAN LYSGAARD MADSEN,\| JENS JUUL HOLST, ${ }^{\ddagger}$ and PER BRØBECH MORTENSEN* \\ *Department of Medicine, Section of Gastroenterology, Rigshospitalet, University Hospital of Copenhagen, Denmark; Departments of \\ ${ }^{\dagger}$ Medical Physiology and \$Medical Anatomy, The Panum Institute, University of Copenhagen, Denmark; "Department of Clinical Physiology \\ and Nuclear Medicine, Hvidovre Hospital, University Hospital of Copenhagen, Denmark; and $\mathbb{I H}_{\mathrm{H}} \mathrm{S}$. Pharmacy, \\ Copenhagen Hospital Corporation, Denmark
}

See editorial on page 1041.

Background \& Aims: Glucagon-like peptide 2 (GLP-2) is intestinotrophic, antisecretory, and transit-modulating in rodents, and it is mainly secreted from the intestinal mucosa of the terminal ileum and colon after food ingestion. We assessed the effect of GLP-2 on the gastrointestinal function in patients without a terminal ileum and colon who have functional short-bowel syndrome with severe malabsorption of wet weight $(>1.5$ $\mathrm{kg} /$ day) and energy ( $>2.3 \mathrm{MJ} /$ day) and no postprandial secretion of GLP-2. Methods: Balance studies were performed before and after treatment with GLP-2, $400 \mu \mathrm{g}$ subcutaneously twice a day for 35 days, in 8 patients (4-17 years from last bowel resection; 6 with Crohn's disease). Four patients received home parenteral nutrition (mean residual jejunum, $83 \mathrm{~cm}$ ), and 4 did not (mean ileum resection, $106 \mathrm{~cm}$ ). Biopsy specimens were taken from jejunal/ileal stomas, transit was measured by scintigraphy, and body composition was measured by dual-energy x-ray absorptiometry. Results: Treatment with GLP-2 improved the intestinal absorption of energy $3.5 \% \pm 4.0 \%$ (mean \pm SD) from $49.9 \%$ to $53.4 \%(P=0.04)$, wet weight $11 \% \pm 12 \%$ from $25 \%$ to $36 \%(P=0.04)$, and nitrogen $4.7 \% \pm 5.4 \%$ from $47.4 \%$ to $52.1 \%(P=0.04)$. Body weight increased $1.2 \pm 1.0$ $\mathrm{kg}(P=0.01)$, lean body mass increased $2.9 \pm 1.9 \mathrm{~kg}$ $(P=0.004)$, fat mass decreased $1.8 \pm 1.3 \mathrm{~kg}(P=$ 0.007 ), and 24-hour urine creatinine excretion increased $(P=0.02)$. The time to $50 \%$ gastric emptying of solids increased $30 \pm 16$ minutes from 89 to 119 minutes $(P<0.05)$. Small bowel transit time was not changed. Crypt depth and villus height were increased in 5 and 6 patients, respectively. Conclusions: Treatment with GLP-2 improves intestinal absorption and nutritional status in short-bowel patients with impaired postprandial GLP-2 secretion in whom the terminal ileum and the colon have been resected.

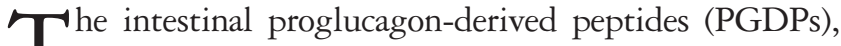
1 comprising glicentin, oxyntomodulin, and the 2 glucagon-like peptides (GLP-1 and GLP-2) are secreted from the intestinal mucosa after food ingestion. ${ }^{1}$ Experimental evidence from both rodent and human studies has linked intestinal adaptation to increased production and secretion of the intestinal PGDPs. ${ }^{2-6}$ Administration of individual synthetic PGDPs to mice by daily subcutaneous injections shows that GLP-2, a peptide of 33 amino acids, ${ }^{7,8}$ is the intestinal PGDP with a significant intestinotrophic activity. GLP-2 administration induces mucosal epithelial proliferation in the stomach, small bowel, and large bowel by stimulation of crypt cell proliferation ${ }^{9}$ and inhibition of enterocyte apoptosis. ${ }^{10}$ Furthermore, treatment with GLP-2 improves absorptive capacity in rats with massive resection of the small intestine. ${ }^{11}$ In addition to these intestinotrophic effects, GLP-2 has inhibitory effects on gastrointestinal motility ${ }^{12}$ and secretion, ${ }^{13}$ and it has been speculated that GLP-2 augments the effects of the 2 other ileal-brake hormones, GLP-1 and peptide YY. Therefore, GLP-2 has received much attention as a potential therapeutic agent in the treatment of patients with short-bowel syndrome. In contrast to short-bowel patients with a preserved colon, patients with a jejunostomy have poor intestinal adaptation, ${ }^{14}$ rapid gastric and intestinal transit, ${ }^{15,16}$ and impaired postprandial GLP-2 secretion. ${ }^{17}$ The present study evaluated the effects of subcutaneous GLP-2 administration on intestinal function in 8 patients with functional short-bowel syndrome and no colon in continuity and extensive resections of the small bowel. It includes a description of the antisecretory, transit-modulating, and intestinotrophic ac-

Abbreviations used in this paper: GLP, glucagon-like peptide; HPN, home parenteral nutrition; PGDP, proglucagon-derived peptide. (C) $\mathbf{2 0 0 1}$ by the American Gastroenterological Association 0016-5085/01/ \$35.00 doi:10.1053/gast.2001.22555 
tions of GLP-2 in these patients, who all had impaired postprandial secretion of GLP-2.

\section{Patients and Methods}

\section{Patients}

Eight patients ( 5 women and 3 men; mean age 49.2 years; range, 32-62 years) participated in the study. Four patients with intestinal failure had been receiving home parenteral nutrition (HPN) for 8.0 years (range, 4-14 years), had an end-jejunostomy, and had residual jejunum measured intraoperatively from the ligament of Treitz of 30, 40, 90, and $170 \mathrm{~cm}$. The other 4 patients were not receiving HPN, had no colon in continuation, and had $65,85,103$, and $170 \mathrm{~cm}$ of the terminal ileum resected. Time from the last bowel resection was 9.6 years (range, $4-17$ years). The cause of the intestinal resection was Crohn's disease in 6 patients, ulcerative colitis with surgical complications in 1 , and ischemic infarction in 1 . All patients selected for the study had functional short-bowel syndrome with fecal losses of energy and wet weight of more than $2.3 \mathrm{MJ} /$ day and $1.5 \mathrm{~kg} /$ day, respectively, demonstrated during a previous admission. ${ }^{18}$ All patients were able to eat food by mouth, i.e., none had pseudo-obstruction. The mean body mass index at the first admission was $20.8 \pm 3.0 \mathrm{~kg} / \mathrm{m}^{2}$. Three of the 4 patients receiving HPN used antisecretory agents (omeprazole intravenously, 2 in combination with subcutaneous octreotide). The last HPN patient and 3 of the 4 patients who were not dependent on HPN used antimotility agents (opium, codeine, and/or loperamide). All patients had continuity of care in our department and were ambulatory, followed up closely, clinically stable, without active inflammatory bowel disease, and judged to be highly compliant with treatments given.

\section{Experimental Design}

The patients were admitted for 5 days and 4 nights in 2 separate study periods 31 days apart. Treatment with GLP-2 was started on day 5 at the end of the first study period, and treatment continued throughout the second period. On the first day of each admission, small bowel biopsy specimens were obtained, and gastrointestinal transit was measured. Balance studies were initiated at 8:30 AM on the morning after the day of admission (day 2) and lasted for 72 hours. Body composition was measured on the third day of each admission. During the 2 balance periods, the patients were allowed identical amounts of their habitual antisecretory and antimotility drugs and parenteral support. Small adjustments were allowed between the balance periods, but patients were requested to report these changes in a diary given to all patients. One patient reduced the amount of parenteral supplement of saline by $1 \mathrm{~L} /$ day, and 2 others reduced the amount of codeine they took. Information on food intake between the 2 study periods, while patients were taking the study drug, was not obtained.

\section{GLP-2}

For these studies we used synthetic human GLP-2, corresponding to human proglucagon $126-158,{ }^{8}$ custom synthesized by PolyPeptide Laboratories GmbH (Wolfenbüttel, Germany). Synthetic human GLP-2, provided as the acetate salt, was mixed with $0.9 \% \mathrm{NaCl}$, and $0.5 \%$ ammonia was added until the peptide dissolved ( $\mathrm{pH}$ approximately 8-9), then $\mathrm{pH}$ was neutralized using $0.1 \mathrm{~mol} / \mathrm{L}$ acetic acid. The preparation was subjected to sterile filtration using a $0.22-\mu \mathrm{m}$ filter (Millipore, Millex, Bedford, MA), dispensed into capped vials, and heat sterilized for 20 minutes at $100^{\circ} \mathrm{C}$. Before use, the filter was saturated with $20 \%$ human albumin (Statens Serum Institut, Copenhagen, Denmark) and washed with sterile water. The preparation was checked for sterility and kept at $-20^{\circ} \mathrm{C}$ until use. The purity and correctness of structure were confirmed by mass sequence and high-performance liquid chromatography analysis (Dr. A. H. Johnsen, Department of Clinical Biochemistry, Rigshospitalet, University of Copenhagen, Denmark). The peptide content after sterile filtration was confirmed by amino acid analysis.

At the end of the first study period (day 5), a fasting blood sample was obtained at 8:30 AM, and treatment with GLP-2 was started by subcutaneous injection of $400 \mu \mathrm{g}$ GLP-2. A second blood sample was drawn 30 minutes later to measure the increase in plasma GLP-2 concentration. When given careful instructions regarding the subcutaneous injections, the patients were discharged with 69 additional vials, each with $400 \mu \mathrm{g}$ of GLP-2, for injection twice a day for 35 days. At least once a week, the patients were contacted by phone to reinforce compliance and to monitor for adverse effects. $\mathrm{Pa}$ tients were asked to describe side effects of the GLP-2 treatment and to record deviations from their daily medical and parenteral prescriptions in the patient diaries. The vials were returned at the end of the study to evaluate compliance. At day 5 , at the end of the second study period, a fasting blood sample was obtained at 8:30 AM, the patients were given a standard large test meal ${ }^{17}$ (a breakfast, $755 \mathrm{~g}$, energy content $3.92 \mathrm{MJ}$ protein:carbohydrate:fat energy ratio 10\%:52\%:37\%, eaten within 15 minutes), and a second blood sample was taken 60 minutes later to evaluate meal-stimulated changes in plasma GLP-2 concentrations. Plasma GLP-2 measurements were performed using a specific $\mathrm{NH}_{2}$-terminal radioimmunoassay as previously described. ${ }^{17}$

\section{Balance Studies}

During the 72-hour balance periods, all oral intake and stomal output were weighed, and the contents of energy (by bomb calorimetry), carbohydrate (by the method of Englyst and Cummings ${ }^{19}$ ), nitrogen (by the method of Kjeldahl ${ }^{20}$ ), fat (gas-liquid chromatography), sodium, and potassium (flame photometry) were determined as previously described. ${ }^{21,22}$ Diet and fecal nitrogen in grams were converted to diet and fecal grams of protein by multiplying by 6.25 . The energy conversion factors were those of Atwater et al., as confirmed by Southgate and Durnin ${ }^{23}: 17.6,23.6$, and $39.1 \mathrm{~kJ} / \mathrm{g}$ for carbo- 
hydrate, protein, and fat, respectively. Twenty-four-hour urinary creatinine was measured at $505 \mathrm{~nm}$ as a pikrat-creatinine complex using a standard hospital analytic technique according to the method of Jaffe.

Patients were given identical diets with a fixed carbohydrate:fat:protein ratio during the 2 balance periods. The energy content and composition of the diet given to each patient were established from a 3-day diet record obtained before admission and adjusted according to an interview with a dietitian at the first admission. At the first admission, patients were informed that they were allowed unrestricted intake of salt and beverages. They were instructed to record and mark the exact type and intake on a checklist and to keep salt and beverage intake constant during the following days and periods of admission. The identically prepared duplicate meals were pooled with the collected duplicate beverages and salt from each 24-hour period. Two patients did not comply with the fixed diet during the second balance period because of reduced appetite. Energy intake was reduced from 13.2 to $12.4 \mathrm{MJ} /$ day in 1 patient, and wet weight intake was reduced from 5.2 to $4.7 \mathrm{~kg}$ /day in another. Stomal outputs were collected on ice and frozen at $-20^{\circ} \mathrm{C}$ every 24 hours. The 324 -hour pooled oral intakes and stomal outputs were thawed and homogenized, and freezedried aliquots were analyzed. The relative absorption of energy, nutrients, and wet weight were the quantities absorbed (oral intake minus stomal excretion) as a percentage of oral intake. Wet weight absorption was the difference between the weight of the oral intake (food and beverages) and the weight of the stomal output.

\section{Gastrointestinal Transit}

Gastrointestinal transit was measured by means of gamma camera technique. Measurements began at $10 \mathrm{Am}$ after an overnight fast on the first day of each admission. At the second admission, the GLP-2 was administered 60 minutes before the meal. The patient ingested a 1.6-MJ meal $(80 \mathrm{~g}$ of bread, $120 \mathrm{~g}$ of egg omelet, $200 \mathrm{~g}$ of water) within 10 minutes. As a solid marker $20 \mathrm{MBq}$ of ${ }^{99 \mathrm{~m}} \mathrm{Tc}$-stannous colloid was fried with the egg omelet, and as a liquid marker $4 \mathrm{MBq}$ of ${ }^{111}$ In-diethylenetriamine pentaacetic acid was added to the water. ${ }^{24}$ Anterior and posterior images were obtained with subjects in the upright position (MaxiCamera 400; General Electric, Milwaukee, WI). Each acquisition lasted 2 minutes, and imaging was repeated at 15-minute intervals for 6 hours. Stomal output was kept out of the field of view by a collecting bag (Assura night bag; Coloplast A/S, Humlebaek, Denmark). Regions of interest for integration of radioactivity were delineated manually around the stomach on each image. At each time point, the fraction of radioactivity passed with the stomal output was calculated as 1 minus the fraction of radioactivity retained in the entire abdomen. All counts were corrected for physical decay and downscatter of ${ }^{111}$ In-activity into the ${ }^{99 \mathrm{~m}} \mathrm{Tc}-$ window. ${ }^{25}$ Geometric means of anterior and posterior counts were used for attenuation correction. Time to $50 \%$ gastric emptying and time to $50 \%$ passed with stomal output were computed from the time-activity curves. Small intestinal transit time was calculated by subtracting time to $50 \%$ gastric emptying from time to $50 \%$ passed with stomal output.

\section{Morphologic Analysis}

At least 2 small bowel biopsy specimens were obtained before and after GLP-2 treatment approximately $10 \mathrm{~cm}$ from the stomal end with a standard endoscopic forceps ( $\mathrm{R} \mathrm{J} \mathrm{Lynx}$ biopsy forceps, 2.2-mm jaw; Microvasive, Boston Scientific, Boston, MA) through fiberoptic video gastroscope (Olympus GIF-Q140). Fixation was in $4 \%$ paraformaldehyde, biopsy specimens were dehydrated and embedded in paraffin, and $10-\mu \mathrm{m}$ sections were cut and placed on gelatin-coated glass and stained with PAS-hematoxylin-aurantia. Each section was visually scanned by a high-resolution camera (Hamamatsu C2400; Hamamatsu Photonics, Hamamatsu City, Japan) connected to a Zeiss Axiophot microscope (Carl Zeiss, Oberkocken, Germany). Calibrations for $10 \times$ images were made by acquiring a micrometer image at this magnification, and morphometric estimates were determined using an imageanalysis program (NIH 1.60; Research Services Branch, Institute of Mental Health, National Institutes of Health, Bethesda, MD). For villus height, the distance from the tip of the villus to the base was measured, and for crypt depth, the distance from the opening of the crypt to the muscularis mucosae was measured. The best-oriented samples were selected for all measurements. Only villi cut in their whole length and 10 representative crypts were measured. The investigator knew the origin of the biopsy specimens but was blinded to the time biopsies were performed and consequently to whether specimens were obtained before or after treatment.

\section{Body Weight and Body Composition}

Fasting body weights were measured every morning after emptying of the bladder and stoma bags, before breakfast, using a leveled platform scale, and were calculated as the mean for 4 consecutive days. Body composition was measured by dual-energy x-ray absorptiometry (Norland XR-36 DXA densitometer; Norland Corp., Fort Atkinson, WI).

\section{Ethics}

The protocol was approved by the Ethics Committee for Medical Research in Copenhagen, Denmark (KF 01-235/ 98). Procedures followed were in accordance with the ethical standards of the Helsinki Declaration of 1975, as revised in 1983. Patients signed informed consent before entrance to the study.

\section{Statistics}

A paired Student $t$ test was used for statistical analysis using the SigmaStat for Windows Version 2.0 (Jandel Corp., Erkrath, Germany). Data are expressed as means \pm SD. A $P$ value of $<0.05$ is considered significant. 
Table 1. Dietary Intake, Fecal Output, and Absorption of Energy, Macronutrients, Wet Weight, and Electrolytes Before and After Treatment With GLP-2

\begin{tabular}{|c|c|c|c|c|}
\hline & Before & After & Effect & $P^{a}$ \\
\hline \multicolumn{5}{|c|}{ Energy $(M J /$ day $)$} \\
\hline Diet & $15.10 \pm 2.70$ & $14.93 \pm 2.84$ & $-0.17 \pm 0.42$ & 0.28 \\
\hline Feces & $7.28 \pm 2.25$ & $6.67 \pm 1.86$ & $-0.62 \pm 0.69$ & 0.04 \\
\hline Absorption & $7.82 \pm 3.60$ & $8.26 \pm 3.45$ & $0.44 \pm 0.63$ & 0.09 \\
\hline \multicolumn{5}{|c|}{ Carbohydrates ( $M J /$ day) } \\
\hline Diet & $6.27 \pm 1.46$ & $6.37 \pm 1.44$ & $0.10 \pm 0.27$ & 0.35 \\
\hline Feces & $1.78 \pm 1.24$ & $1.53 \pm 0.78$ & $-0.25 \pm 0.53$ & 0.22 \\
\hline Absorption & $4.49 \pm 1.92$ & $4.83 \pm 1.70$ & $0.35 \pm 0.44$ & 0.06 \\
\hline \multicolumn{5}{|c|}{ Protein (MJ/day) } \\
\hline Diet & $2.56 \pm 0.46$ & $2.54 \pm 0.52$ & $-0.02 \pm 0.16$ & 0.73 \\
\hline Feces & $1.27 \pm 0.53$ & $1.12 \pm 0.45$ & $-0.14 \pm 0.13$ & 0.02 \\
\hline Absorption & $1.29 \pm 0.82$ & $1.42 \pm 0.82$ & $0.12 \pm 0.22$ & 0.16 \\
\hline \multicolumn{5}{|l|}{ Fat $(M J / d a v)$} \\
\hline Diet & $4.38 \pm 0.94$ & $4.29 \pm 0.96$ & $-0.08 \pm 0.19$ & 0.26 \\
\hline Feces & $3.21 \pm 1.08$ & $3.10 \pm 1.19$ & $-0.11 \pm 0.26$ & 0.28 \\
\hline Absorption & $1.17 \pm 0.71$ & $1.19 \pm 0.82$ & $0.03 \pm 0.39$ & 0.85 \\
\hline \multicolumn{5}{|c|}{ Wet weight $(\mathrm{kg} /$ day $)$} \\
\hline Diet & $4.46 \pm 0.76$ & $4.39 \pm 0.69$ & $-0.07 \pm 0.16$ & 0.25 \\
\hline Feces & $3.25 \pm 1.59$ & $2.76 \pm 1.17$ & $-0.49 \pm 0.53$ & 0.04 \\
\hline Absorption & $1.21 \pm 1.66$ & $1.63 \pm 1.29$ & $0.42 \pm 0.48$ & 0.04 \\
\hline \multicolumn{5}{|c|}{ Sodium ( $\mathrm{mmol} /$ day) } \\
\hline Diet & $245 \pm 93$ & $233 \pm 86$ & $-12 \pm 14$ & 0.05 \\
\hline Feces & $298 \pm 86$ & $254 \pm 74$ & $-45 \pm 52$ & 0.047 \\
\hline Absorption & $-53 \pm 133$ & $-21 \pm 121$ & $33 \pm 49$ & 0.10 \\
\hline \multicolumn{5}{|c|}{ Potassium (mmol/day) } \\
\hline Diet & $125 \pm 33$ & $120 \pm 36$ & $-4 \pm 5$ & 0.07 \\
\hline Feces & $49 \pm 26$ & $40 \pm 26$ & $9 \pm 12$ & 0.08 \\
\hline Absorption & $75 \pm 48$ & $80 \pm 45$ & $5 \pm 10$ & 0.22 \\
\hline \multicolumn{5}{|c|}{ Calcium ( $\mathrm{mmol} /$ day $)$} \\
\hline Diet & $71 \pm 51$ & $65 \pm 37$ & $-7 \pm 44$ & 0.68 \\
\hline Feces & $72 \pm 47$ & $63 \pm 42$ & $-9 \pm 11$ & 0.06 \\
\hline Absorption & $0 \pm 18$ & $2 \pm 25$ & $2 \pm 37$ & 0.87 \\
\hline
\end{tabular}

NOTE. Data represent means \pm SD.

apaired Student $t$ test.

\section{Results}

\section{Intestinal Absorption}

The absolute amounts of diet intake, stomal output (i.e., what was malabsorbed) and the calculated amount absorbed (diet minus output) of energy ( $\mathrm{MJ} /$ day), macronutrients ( $\mathrm{MJ} /$ day), wet weight ( $\mathrm{kg} /$ day), and electrolytes ( $\mathrm{mmol} /$ day) before and after treatment with GLP-2 are shown in Table 1. The relative absorption of these parameters is shown in Figures 1 and 2. As evidenced, the patients studied had severe malabsorption. In general, malabsorption of half of the energy intake and three quarters of the intake of wet weight was observed with considerable variations between the individuals. Diet analyses confirmed that the intake in the 2 study periods was constant as intended, although the intake of sodium and potassium tended to be lower in the second balance study. GLP-2 reduced stomal output of energy with $0.62 \pm 0.69 \mathrm{MJ} /$ day $(P=0.04)$ and tended to improve absorption of the absolute amount of energy with $0.44 \pm 0.63 \mathrm{MJ} /$ day $(P=0.09$; Table 1$)$. Thus, treatment with GLP-2 increased energy absorption by $3.5 \% \pm 4.0 \%$ from $49.9 \% \pm 20.3 \%$ to $53.4 \% \pm 18.1 \%$ $(P=0.04$; Figure 1$)$ equivalent to an increase of $13.1 \%$ $\pm 22.3 \%$ in percentage of absorption at baseline $(49.9 \%)$. Absorption of carbohydrates improved by $0.35 \pm 0.44 \mathrm{MJ} /$ day $(P=0.06)$, which was borderline significant, whereas the relative absorption showed a nonsignificant increasing trend of $4.4 \% \pm 7.5 \%(P=$ 0.14 ) from $69.7 \% \pm 22.0 \%$ to $74.1 \% \pm 15.9 \%$. Excretion of protein (nitrogen) decreased $0.14 \pm 0.13 \mathrm{MJ} /$ day $(P=0.02)$, but the effect on the absolute absorption did not reach statistical significance $(P=0.16)$. This was in contrast to the improvement in the relative absorption of protein (Figure 1), which increased by $4.7 \% \pm 5.4 \%$ from $47.4 \% \pm 29.3 \%$ to $52.1 \% \pm 28.4 \%(P=0.04)$. The effect of GLP-2 on fat absorption was negligible. Thus, the increase in fat absorption of $1.3 \% \pm 8.0 \%(P=0.66)$ from $26.9 \% \pm 16.8 \%$ to $28.2 \% \pm 19.8 \%$ was not significant. 


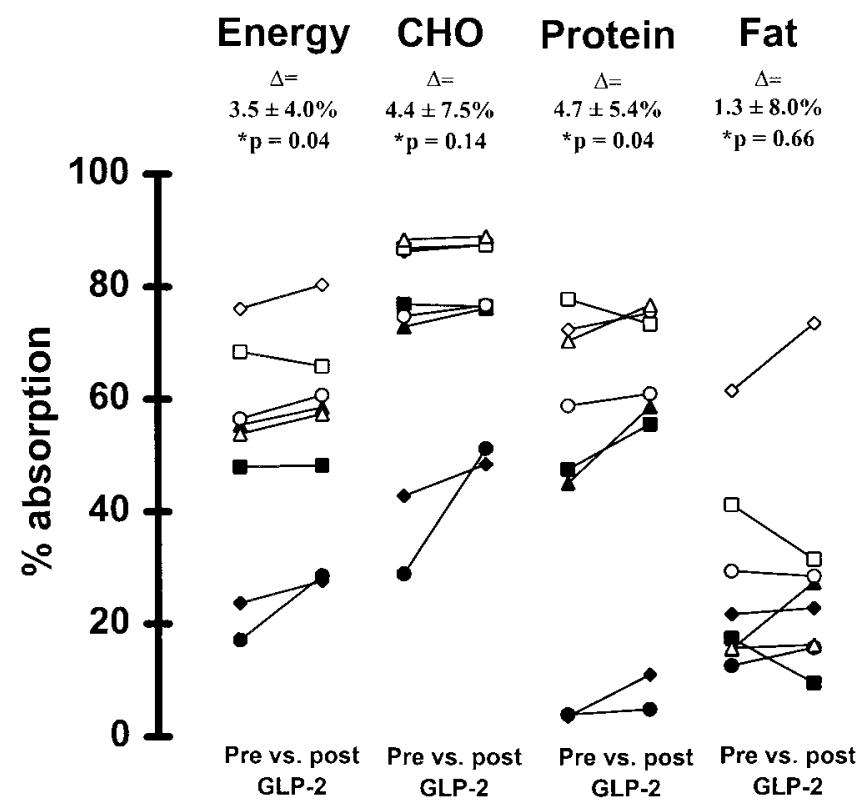

Figure 1. Relative absorption of energy and macronutrients before and after 5 weeks of GLP-2 treatment in 8 patients with the shortbowel syndrome. Closed symbols represent patients receiving HPN. $*$ Paired Student $t$ test. $\Delta$, Mean \pm SD effect of treatment with GLP-2 compared with baseline.

GLP-2 diminished the stomal excretion of wet weight by $0.49 \pm 0.53 \mathrm{~kg} /$ day $(P=0.04)$ from $3.25 \pm 1.59$ to $2.76 \pm 1.17 \mathrm{~kg} /$ day. Thus, GLP-2 improved wet weight absorption in 7 of 8 patients (Figure 2), and the mean improvement in the wet weight absorption was $0.42 \pm$ $0.48 \mathrm{~kg} /$ day $(P=0.04)$. The overall wet weight absorption increased from $1.21 \pm 1.66$ to $1.63 \pm 1.29 \mathrm{~kg} /$ day. This corresponded to an increase in the relative mean wet weight absorption of $10.6 \% \pm 11.6 \%(P=0.04)$ from $25.4 \% \pm 37.3 \%$ to $35.9 \% \pm 28.1 \%$.

Sodium intake tended to be reduced during the second balance study period $(P=0.05)$. The stomal excretion of sodium was reduced by $45 \pm 52 \mathrm{mmol} /$ day $(P=0.047)$ from $298 \pm 86$ to $254 \pm 74 \mathrm{mmol} /$ day, and the absolute sodium absorption tended to increase $(P=0.10)$. The relative absorption of sodium improved in 6 patients (Figure 2), but the average improvement of $13.2 \% \pm$ $20.7 \%(P=0.11)$ from $-36.2 \% \pm 64.7 \%$ to $-23.0 \%$ $\pm 60.9 \%$ (less net secretion) did not quite reach the chosen level of statistical significance.

Both intake and excretion of potassium tended to decrease $(P=0.07-0.08)$. Absorption increased significantly in percentage (Figure 2) but not in absolute amounts (Table 1). Absorption of potassium improved in 7 patients (Figure 2), and on average by $4.85 \% \pm 10.2 \%$ $(P=0.04)$ from $75.4 \% \pm 47.9 \%$ to $80.3 \% \pm 44.6 \%$.

The stomal calcium excretion tended to be reduced by
$9 \pm 11 \mathrm{mmol} / \mathrm{L}(P=0.06)$ during the second balance period. No significant change in the absolute calcium absorption was seen after GLP-2 treatment. The relative calcium absorption increased in 6 patients (Figure 2), but the average increase of $2.7 \% \pm 44.4 \%$ from $0.4 \% \pm$ $23 \%$ to $3.1 \% \pm 34.3 \%$ did not reach statistical significance.

Thirty-two correlations between the individual patient responses regarding the effect on energy, carbohydrate, nitrogen, wet weight, sodium, potassium, and calcium absorption and either the length of the residual jejunum or the dose of GLP-2 per kilogram of body weight were investigated. Six of these correlations were significant. A negative correlation was found between the residual jejunal length and the effect of GLP-2 on the absolute $(r=0.85 ; P=0.002)$ and relative wet weight absorption $(r=0.85 ; P=0.002)$, indicating that patients with the shortest bowel benefitted more in wet weight absorption. A positive correlation was found between the residual jejunal length and the absolute $(r=$ $0.73 ; P=0.02)$ and relative $(r=0.79 ; P=0.01)$ calcium absorption. A positive correlation was found between the dose of GLP-2 per kilogram of body weight and the absolute $(r=0.81 ; P=0.01)$ and relative $(r=$ $0.83 ; P=0.005)$ fat absorption. None of the other correlations of absorptive parameters were significant.

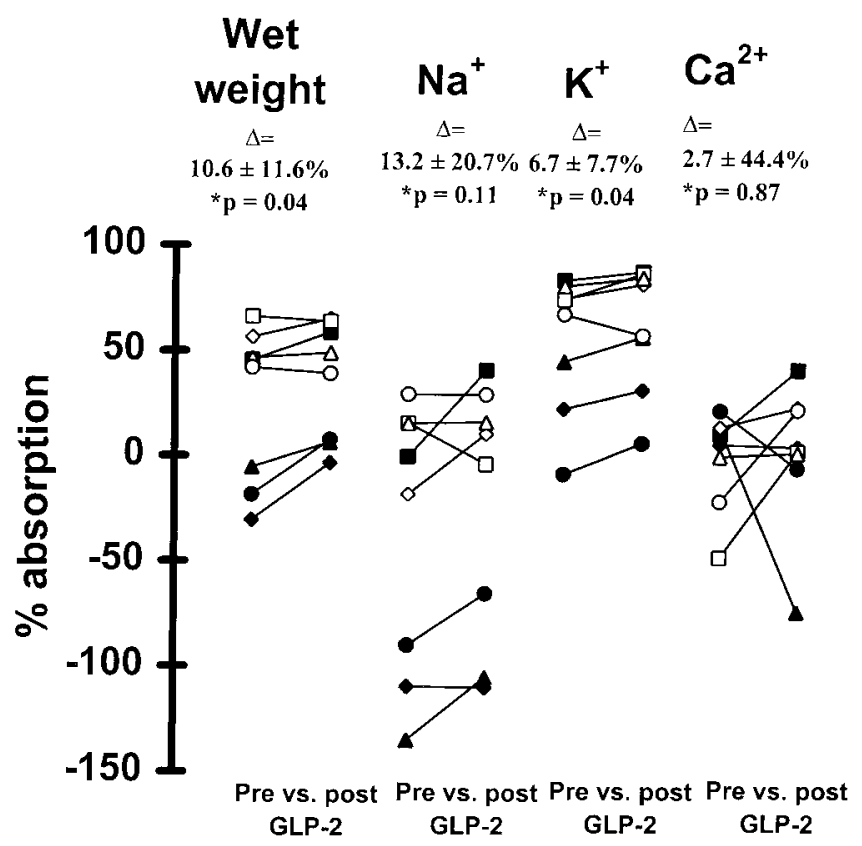

Figure 2. Relative absorption of wet weight, sodium, potassium, and calcium before and after 5 weeks of GLP-2 treatment in 8 patients with the short-bowel syndrome. Closed symbols represent patients receiving HPN. *Paired Student $t$ test. $\Delta$, Mean \pm SD effect of treatment with GLP-2 compared with baseline. 


\section{Gastrointestinal Transit}

Transit was only measured in 7 patients, because intestinal anatomy did not permit a clear delineation of the regions for integration of radioactivity in 1 patient. GLP-2 increased the time to $50 \%$ gastric emptying of solids in all 7 patients with $30 \pm 16$ minutes $(P=$ 0.002; Figure 3), from $89 \pm 62$ to $119 \pm 60$ minutes. The time to $50 \%$ gastric emptying of liquids increased in 6 of 7 patients (Figure 3 ) and averaged $15 \pm 37$ minutes, a nonsignificant $(P=0.33)$ increase from $45 \pm 37$ to $60 \pm 12$ minutes. The change in time to $50 \%$ passed with stomal output was small and not significant, for solids it increased $10 \pm 67$ minutes $(P=0.69)$ from $175 \pm 77$ to $186 \pm 79$ minutes, and for liquids it decreased $18 \pm 56$ minutes $(P=0.43)$ from $143 \pm 82$ to $125 \pm 45$ minutes. Consequently, small bowel transit time actually tended to decrease for both the solid (19 \pm 60 minutes, from $86 \pm 73$ to $67 \pm 55$ minutes; $P=$ $0.43)$ and liquid $(33 \pm 58$ minutes, from $98 \pm 85$ to $65 \pm 44$ minutes; $P=0.34$ ) markers.

\section{Morphologic Analysis}

GLP-2 increased villus height in 6 of 8 patients (Figure 4), but the overall increase of $50 \pm 85 \mu \mathrm{m}$ from $457 \pm 60$ to $506 \pm 116 \mu \mathrm{m}$ did not reach statistical significance $(P=0.14)$. Crypt depth increased in 5 patients, was unaffected in 1 , and decreased in 2 , and on

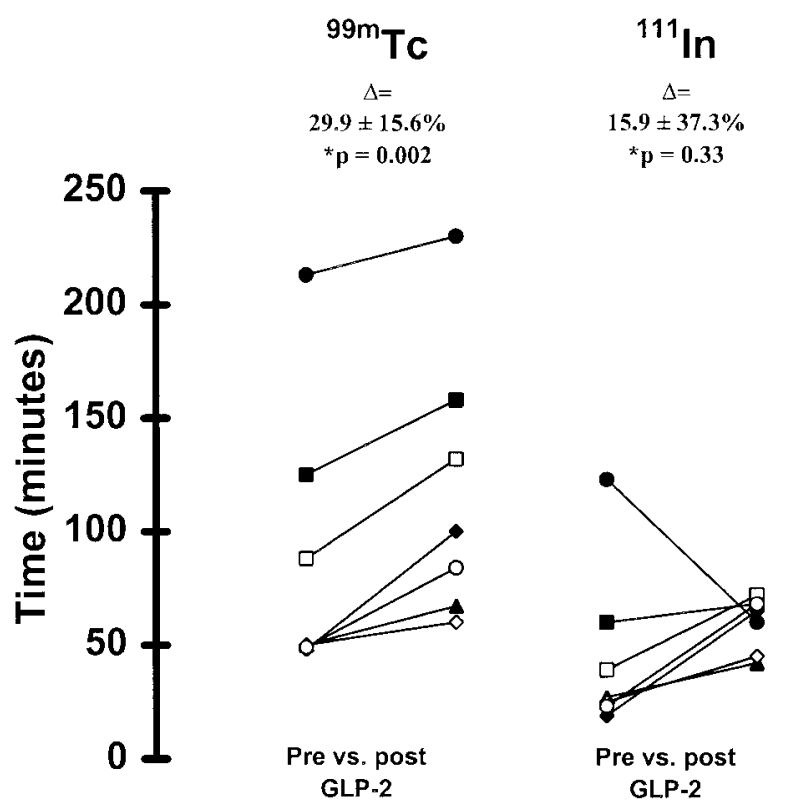

Figure 3. Time to $50 \%$ gastric emptying of the solid marker $(20 \mathrm{MBq}$ of ${ }^{99 \mathrm{~m} T c-s t a n n o u s ~ c o l l o i d) ~ a n d ~ l i q u i d ~ m a r k e r ~(4 ~ M B q ~ o f ~}{ }^{111}$ In-diethylenetriamine pentaacetic acid) before and after 5 weeks of GLP-2 treatment in 7 patients with the short-bowel syndrome. Closed symbols represent patients receiving HPN. *Paired Student $t$ test. $\Delta$, Mean \pm SD effect of treatment with GLP-2 compared with baseline.

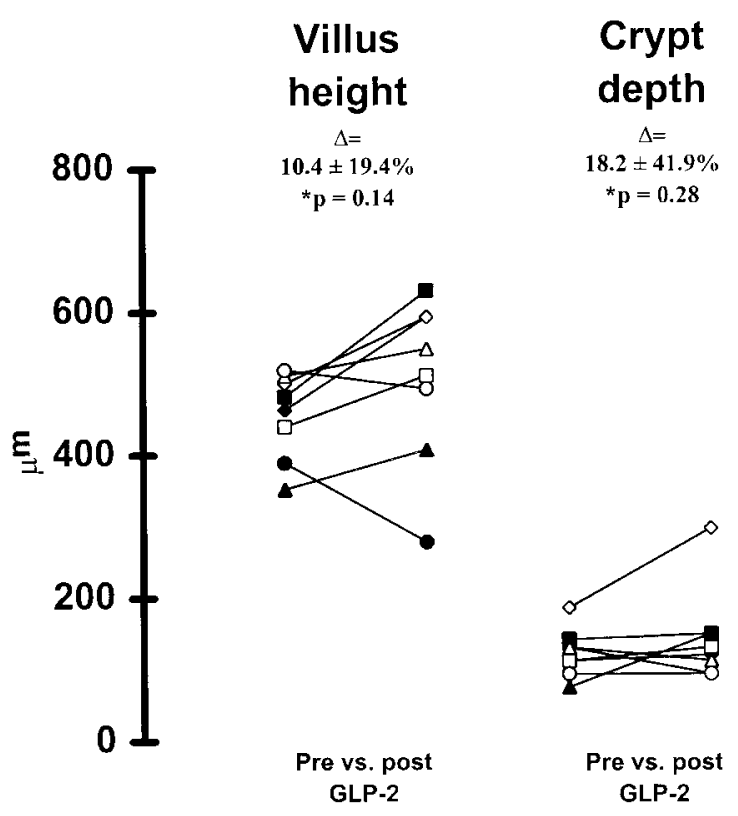

Figure 4. Measurements of the villus heights and crypt depths before and after 5 weeks of treatment with GLP-2 in 8 patients with the short-bowel syndrome. Closed symbols represent patients receiving HPN. *Paired Student $t$ test. $\Delta$, Mean \pm SD effect of treatment with GLP-2 compared with baseline.

average the increment of $20 \pm 49 \mu \mathrm{m}$ from $122 \pm 34$ to $142 \pm 34 \mu \mathrm{m}$ was not significant $(P=0.28)$.

\section{Body Weight, Body Composition, and Urinary Creatinine Excretion}

Body weight in all 8 patients increased after GLP-2 treatment a mean of $1.2 \pm 1.0 \mathrm{~kg}(P=0.01)$ from $58.9 \pm 9.0$ to $60.1 \pm 9.3 \mathrm{~kg}$. Lean body mass improved $2.9 \pm 1.9 \mathrm{~kg}(P=0.004)$ from $36.8 \pm 8.4$ to $39.7 \pm 8.7 \mathrm{~kg}$, and fat mass decreased by $1.8 \pm 1.3 \mathrm{~kg}$ $(P=0.007)$ from $19.9 \pm 9.1 \mathrm{~kg}$ at baseline to $18.1 \pm$ $8.7 \mathrm{~kg}$. Urinary 24-hour creatinine excretion increased by $0.7 \pm 0.7 \mathrm{mmol} / \mathrm{day}(P=0.02)$ from $8.6 \pm 1.2$ to $9.3 \pm 1.9 \mathrm{mmol} /$ day. Bone mass increased from $2.3 \pm$ 0.3 to $2.4 \pm 0.4 \mathrm{~kg}(P=0.02)$. Seven of 8 patients improved in any of the above parameters.

\section{Hormone Analysis}

Fasting plasma GLP-2 concentrations were measured twice; before the test meal and before the subcutaneous GLP-2 injections. Mean GLP-2 concentration was $11 \pm 5 \mathrm{pmol} / \mathrm{L}$ (range, $5-20 \mathrm{pmol} / \mathrm{L}$ ) at fasting and $12 \pm 5 \mathrm{pmol} / \mathrm{L}$ (range, $5-21 \mathrm{pmol} / \mathrm{L}$ ) 60 minutes after the test meal $(P=0.68)$, i.e., postprandial GLP-2 secretion was negligible in all 8 patients. In contrast, subcutaneous injection of $400 \mu \mathrm{m}$ of GLP-2 significantly increased plasma GLP-2 concentrations from $14 \pm 7$ $\mathrm{pmol} / \mathrm{L}$ (range, $6-26 \mathrm{pmol} / \mathrm{L}$ ) at fasting to $719 \pm 281$ 


\section{Plasma GLP-2 concentrations}

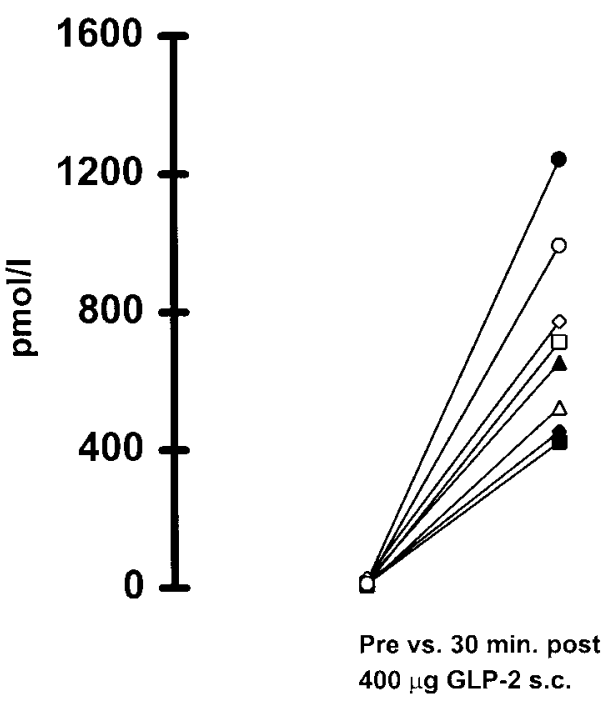

Figure 5. Plasma GLP-2 levels at fasting and 30 minutes after subcutaneous injection of $400 \mu \mathrm{g}$ GLP-2.

pmol/L (range, 420-1240 pmol/L; $P<0.001$ ) 30 minutes after the injection. For comparison, in 7 healthy subjects a similar test meal increased plasma GLP-2 from $9 \pm 4 \mathrm{pmol} / \mathrm{L}$ to $53 \pm 23 \mathrm{pmol} / \mathrm{L} .{ }^{17}$ The increments in plasma GLP-2 achieved in each subject after GLP-2 injection are shown in Figure 5.

\section{Compliance and Adverse Effects}

Compliance was excellent as evaluated by counting of the returned empty vials and by evaluation of patient diaries. Thus, in 6 of the 8 patients, all 70 injections were taken, and 2 patients each missed a single injection. Two patients experienced self-limited local reactions with erythema and tenderness corresponding to the injection sites after approximately 2 weeks of treatment. One patient described a diminished appetite after 2 weeks of treatment, and because of larger nocturnal urinary volumes, she reduced the parenteral saline load by $1 \mathrm{~L} /$ day. Six of the 8 patients recorded a weight gain using their own scales at home. None of the patients had edema at a clinical examination during the second study period.

Results of the following standard blood tests did not change: hemoglobin, thrombocytes, leukocytes, international normalized ratio, prothrombin time, erythrocyte sedimentation rate, orosomucoid, protein, alanine aminotransferases, alkaline phosphatases, bilirubin, potassium, total and ionized calcium, phosphate, zinc, magnesium, and bicarbonate. Levels of parathyroid hormone (4.0 and $3.3 \mathrm{pmol} / \mathrm{L}$ before and after treatment, respec- tively; $P=0.35), 25$-hydroxy-vitamin $\mathrm{D}(22.8$ and 25.3 $\mathrm{ng} / \mathrm{mL} ; P=0.40)$, and 1-25-hydroxy-vitamin $\mathrm{D}(22.6$ and $30.6 \mathrm{pg} / \mathrm{mL} ; P=0.62$ ) also did not change significantly. Serum sodium concentrations tended to increase from $138 \pm 2$ to $140 \pm 2 \mathrm{mmol} / \mathrm{L}(P=0.056)$, and serum albumin concentration increased from $575 \pm 58$ to $610 \pm 51 \mu \mathrm{mol} / \mathrm{L}(P=0.005)$.

\section{Discussion}

Patients with intestinal failure frequently require life-long parenteral nutrition. Although providing good nutritional recovery, the complex technology of HPN reduces the quality of life, ${ }^{26}$ and serious side effects, such as sepsis, venous thrombosis, and liver disease may occur. ${ }^{27-30}$ Small bowel transplantation is an exciting alternative, but many still consider it experimental for most short-bowel patients until it has proven superior to parenteral nutrition in terms of quality of life and mortality. ${ }^{27}$ Therefore, the search for factors to enhance small bowel adaptation and to increase the assimilation of macronutrients and absorption of water and electrolytes, thereby decreasing the need for parenteral nutrition, has been intensive. The concept of "bowel rehabilitation" was introduced by Byrne et al. ${ }^{31,32}$ with the introduction of growth hormone and glutamine in the treatment of short-bowel patients. However, their encouraging results have been disputed in later randomized, double-blinded studies. ${ }^{33-35}$

The recent discoveries of the tissue-specific intestinotrophic, antisecretory, and transit-modulating effects of GLP-2 have been followed with great interest. ${ }^{36,37}$ GLP-2 is secreted from the intestinal mucosa in response to food ingestion, and we recently found that postprandial GLP-2 secretion is impaired in patients with no terminal ileum and no colon. ${ }^{17}$ The well-known concomitant poor intestinal adaptation ${ }^{14}$ and the rapid gastric and intestinal transit described in these patients who have jejunostomies ${ }^{15,16}$ prompted us to evaluate the effect of GLP-2 in this subgroup of short-bowel patients. As expected, none of the patients studied had a preserved meal-stimulated GLP-2 response. The maximum increase in GLP-2 concentration after meal stimulation was only $9 \mathrm{pmol} / \mathrm{L}$, compared with a mean increase of 44 $\mathrm{pmol} / \mathrm{L}$ (range, $1-77 \mathrm{pmol} / \mathrm{L}$ ) in healthy controls. ${ }^{17}$ In comparison, supraphysiologic plasma GLP-2 concentrations of $420-1240 \mathrm{pmol} / \mathrm{L}$ were obtained $30 \mathrm{~min}$ utes after subcutaneous injection of $400 \mu \mathrm{g}$ of GLP-2 (Figure 5).

Treatment with GLP-2 increased the relative intestinal energy absorption from $49.9 \%$ to $53.4 \%$ (Figure 1). In absolute units of measurement, GLP-2 increased en- 
ergy absorption by $0.44 \mathrm{MJ} / \mathrm{day}$, which mainly consisted of carbohydrates $(0.35 \mathrm{MJ} /$ day $)$ and protein $(0.12 \mathrm{MJ} /$ day), whereas GLP-2 had no effect on fat absorption $(0.03 \mathrm{MJ} /$ day; Table 1$)$. The improvement in the amount of energy absorbed was obtained in spite of a nonsignificant decrease in intake of $0.17 \mathrm{MJ} /$ day, which means that the reduction in the energy malabsorbed (equal to the stomal excretion) was proportionally larger, 0.62 $\mathrm{MJ} /$ day (Table 1).

Treatment with GLP-2 also had a considerable effect on wet weight absorption, which increased from $25 \%$ to $36 \%$ (Figure 2), a gain of $0.42 \mathrm{~kg} /$ day caused by an improvement from 1.21 to $1.63 \mathrm{~kg} /$ day (Table 1). Correspondingly, stomal outputs decreased by $0.49 \mathrm{~kg} /$ day (Table 1), which is a remarkable effect in steady-state patients already optimally treated by conventional medication.

Several physiologic mechanisms possibly accounting for the effects of GLP-2 were addressed. GLP-2 may diminish gastric acid secretion, as demonstrated in sham feeding of healthy humans. ${ }^{13}$ However, the largest effect on intestinal wet weight absorption $(0.82$ and $1.25 \mathrm{~kg} /$ day, respectively) was demonstrated in the 2 patients already treated with a combination of the antisecretory agents omeprazole and octreotide, which may render this explanation less attractive. Consequently, the pharmacologic effects of GLP-2 administered as subcutaneous injections did not appear to be hindered by octreotide, although it is possible that octreotide inhibits physiologic, food-stimulated GLP-2 secretion in patients with a preserved terminal ileum or colon. Another important difference from conventional antisecretory treatment was that GLP-2 improved both wet weight and energy absorption, in contrast to $\mathrm{H}_{2}$-receptor antagonists and proton pump inhibitors, which have no effects on energy absorption in patients with intestinal resection. ${ }^{22}$

GLP-2 prolonged gastric emptying time of solids (Figure 3), and gastric emptying time of liquids was prolonged in all but 1 of the patients. However, the combined gastric emptying and small bowel transit time was not changed by GLP-2, and small bowel transit time consequently tended to decrease. Hence, the effect of GLP-2 on transit time in short-bowel patients was complex, and it is not clear whether this effect has a role in the improved absorption of energy and wet weight. GLP-1 is known to modify gut transit. It could be speculated that the effect of GLP-2 is indirect and mediated by GLP-1. However, it has previously been shown that GLP-2 does not stimulate release of GLP-1. ${ }^{13}$ Changes in gastric emptying could influence dietary intake while patients are taking the study drug. The spontaneous dietary intake of the patients between the 2 study periods was not evaluated, but, as described, 2 patients did not comply with the fixed diet during the second balance period because of reduced appetite. Therefore, future studies should evaluate the effect of GLP-2 on oral intake because a reduction in intake not based on an improvement in the nutritional status might jeopardize the overall effect on short-bowel patients who are depending on hyperphagia.

We believe the intestinotrophic effect of GLP-2 is responsible for some of its effect on intestinal absorption, but statistical analysis in the limited number of patients was unable to provide sufficient proof. Morphometric analysis showed that villus height and crypt depth increased in 6 and 5 of the 8 patients, respectively (Figure 4), which on an average was increased by $18 \%$ and $10 \%$, respectively.

The nutritional benefits of increased intestinal absorption in short-bowel patients should be reflected in changes in body weight and composition, and ultimately in quality of life. However, quality of life was not measured in this study. The increase in body weight and lean body and bone mass and the reduction in fat mass seen as a result of the 5-week treatment with GLP-2 were taken as clinical indications of a beneficial effect, which most probably was mediated through the effect on intestinal absorption. When the nitrogen gain during the 35 days of treatment is calculated based on a $4.7 \%$ improvement in nitrogen absorption, this could be estimated to approximately $200 \mathrm{~g}$ of protein. Given an $80 \%$ hydration state of lean tissue (e.g., muscle) this only translates to a $1-\mathrm{kg}$ gain of lean body mass over the 35 days. The DEXA scan showed a gain of $2.9 \mathrm{~kg}$. When considering changes in total energy absorption, the $3.5 \%$ increase could be estimated to approximately $15 \mathrm{MJ}$ over the 35 days of treatment. If this amount of energy were converted solely to protein, it would correspond to approximately $600 \mathrm{~g}$, which again could translate to a $3-\mathrm{kg}$ gain of lean body mass. Changes in lean body mass may also be estimated from changes in urinary creatinine excretion. From the equation of Forbes and Bruining, ${ }^{38}$ the mean increase in urinary creatinine excretion of 0.71 $\mathrm{mmol} /$ day would correspond to an increase in lean body mass of $2.3 \mathrm{~kg} /$ day. The absence of clinical signs of edema supported that the increase in lean body mass, measured by dual-energy x-ray absorptiometry, actually reflected an increase in muscle mass. However, dualenergy $\mathrm{x}$-ray absorptiometry can overestimate lean body mass if water is retained. Thus, a concomitant measure of total body water would have been optimal, but this was not performed in this study. Furthermore, objective mea- 
sures of muscle strength would have been of value. The changes in bone mass were discrete but significant. Whether the small but insignificant increases in $25-\mathrm{OH}$ and $1,25-\mathrm{OH}$ vitamin $\mathrm{D}$ plasma concentrations, increased calcium absorption, or increased physical activity could contribute to this finding remains to be established. Increases in serum albumin and sodium levels also found in this study were encouraging.

In contrast to the 2 double-blind, randomized studies using high-dose growth hormone and glutamine, ${ }^{33,34}$ treatment with GLP-2 significantly increased overall energy absorption in this study. In another open-labeled study, ${ }^{32}$ the combination of growth hormone, glutamine, and high-carbohydrate diet improved energy absorption approximately $590 \mathrm{KJ} /$ day in 8 short-bowel patients who all had preserved colonic continuity, which possibly was a result of the increase in carbohydrate intake known to increase energy absorption in patients with a colon. ${ }^{39}$ In comparison, we found that GLP-2 increased absorption $440 \mathrm{~kJ} /$ day on a fixed diet.

GLP-2 significantly increased wet weight absorption with $0.42 \mathrm{~kg} /$ day, which is less than the $0.7 \mathrm{~kg} /$ day reported in the uncontrolled study with high-dose growth hormone in which patients, in addition to the mentioned dietary changes, also received oral rehydration solutions (Gatorade; The Gatorade Company, Chicago, IL) as a part of active treatment. ${ }^{32}$ The 2 blinded studies using growth hormone and glutamine resulted in symptoms of fluid retention known to occur during treatment with growth hormone, but a beneficial effect on intestinal absorption of wet weight was not documented. ${ }^{33,34}$

The observed effects on body weight and body composition resembled effects obtained in studies using growth hormone, ${ }^{40,41}$ but in contrast to findings after treatment with growth hormone, no clinical signs of edema occurred during GLP-2 treatment. Furthermore, GLP-2 increased urinary creatinine excretion, indicating that GLP-2 increased muscle mass and did not just change hydration. Creatinine excretion was measured in one of the studies using high-dose growth hormone and found not to be changed according to improvements in lean body mass measured by DEXA scan. ${ }^{41}$ The mechanism behind the remarkable effect of GLP-2 on body composition was not examined in this study (e.g., a possible stimulatory effect on the secretion of insulin, growth hormone, or insulin-like growth factor 1).

The dose of GLP-2 was decided from data from pharmacokinetics studies of GLP-2 administered subcutaneously in healthy volunteers, whereas the duration of therapy in this study was chosen arbitrarily. As recently described by Hartmann et al., ${ }^{8}$ subcutaneous injections of $400 \mu \mathrm{g}$ of GLP-2 increased intact plasma GLP-2 to a maximum at 45 minutes. At 60 minutes, plasma contained $69 \% \pm 1 \%$ intact GLP-2. ${ }^{8}$ To our knowledge, this is the first study on the effects of GLP-2 in shortbowel patients, and the optimal duration and concentration requirements for GLP-2 to induce beneficial effects on intestinal secretion, motility, morphology, and most importantly absorption are not known. Additional studies are needed to show if more frequent administration, a higher dose, or a longer duration of treatment with GLP-2 will further improve the effects on intestinal function. Development of GLP-2 analogues characterized by prolonged release or slower degradation may also be an interesting approach to improve the effect.

The factors determining whether short-bowel patients are dependent on parenteral nutrition are residual absorption of energy, water, and sodium, and the borderline between dependence on and independence of parenteral nutrition has proven to be rather definite, narrow, and measurable. ${ }^{18}$ Some patients have almost no residual bowel function and are beyond the point at which dietary and pharmacologic treatment will result in a tapering off of parenteral nutrition. Other patients have a residual bowel function close to the borderline, above which they become independent of parenteral nutrition. In our view, this is the subset of short-bowel patients who may have the main benefit of GLP-2 treatment, which might improve intestinal function to cross the borderline, the point at which parenteral nutrition is no longer obligatory. Future studies are needed to show if optimal dosage and administration of this new treatment to short-bowel patients eventually result in long-term improvements in nutritional status and independence from parenteral nutrition in a fraction of patients with the short-bowel syndrome.

\section{References}

1. Holst JJ. Enteroglucagon. Annu Rev Physiol 1997;59:257-271.

2. Gleeson MH, Bloom SR, Polak JM, Henry K, Dowling RH. Endocrine tumour in kidney affecting small bowel structure, motility, and absorptive function. Gut 1971;12:773-782.

3. Stevens FM, Flanagan RW, O'Gorman D, Buchanan KD. Glucagonoma syndrome demonstrating giant duodenal villi. Gut 1984;25:784-791.

4. Taylor RG, Verity K, Fuller PJ. Ileal glucagon gene expression: ontogeny and response to massive small bowel resection. Gas troenterology 1990;99:724-729.

5. Rountree DB, Ulshen MH, Selub S, Fuller CR, Bloom SR, Ghatei MA, Lund PK. Nutrient-independent increases in proglucagon and ornithine decarboxylase messenger RNAs after jejunoileal resection. Gastroenterology 1992;103:462-468.

6. Bloom SR, Polak JM. The hormonal pattern of intestinal adaptation. A major role for enteroglucagon. Scand J Gastroenterol Suppl 1982;14:93-103.

7. Buhl T, Thim L, Kofod H, Orskov C, Harling H, Holst JJ. Naturally 
occurring products of proglucagon 111-160 in the porcine and human small intestine. J Biol Chem 1988;263:8621-8624.

8. Hartmann B, Johnsen AH, Orskov C, Adelhorst K, Thim L, Holst JJ. Structure, measurement, and secretion of human glucagon-like peptide-2. Peptides 2000;21:73-80.

9. Drucker DJ, Erlich P, Asa SL, Brubaker PL. Induction of intestinal epithelial proliferation by glucagon-like peptide 2. Proc Natl Acad Sci U S A 1996;93:7911-7916.

10. Tsai $\mathrm{CH}$, Hill M, Asa SL, Brubaker PL, Drucker DJ. Intestinal growth-promoting properties of glucagon-like peptide-2 in mice. Am J Physiol 1997;273:E77-E84.

11. Scott RB, Kirk D, MacNaughton WK, Meddings JB. GLP-2 augments the adaptive response to massive intestinal resection in rat. Am J Physiol 1998;275:G911-G921.

12. Wojdemann M, Wettergren A, Hartmann B, Holst JJ. Glucagon-like peptide- 2 inhibits centrally induced antral motility in pigs. Scand J Gastroenterol 1998;33:828-832.

13. Wojdemann M, Wettergren A, Hartmann B, Hilsted L, Holst JJ. Inhibition of sham feeding-stimulated human gastric acid secretion by glucagon-like peptide-2. J Clin Endocrinol Metab 1999;84: 2513-2517.

14. Hill GL, Mair WS, Goligher JC. Impairment of "ileostomy adaptation" in patients after ileal resection. Gut 1974;15:982-987.

15. Nightingale JM, Kamm MA, van der Sijp JR, Morris GP, Walker ER, Mather SJ, Britton KE, Lennard Jones JE. Disturbed gastric emptying in the short bowel syndrome. Evidence for a "colonic brake." Gut 1993;34:1171-1176.

16. Scolapio JS, Camilleri M, Fleming CR. Gastrointestinal motility considerations in patients with short-bowel syndrome. Dig Dis 1997;15:253-262.

17. Jeppesen PB, Hartmann B, Hansen BS, Thulesen J, Holst JJ, Mortensen PB. Impaired meal stimulated glucagon-like peptide 2 response in ileal resected short bowel patients with intestinal failure. Gut 1999;45:559-563.

18. Jeppesen PB, Mortensen PB. Intestinal failure defined by measurements of intestinal energy and wet weight absorption. Gut 2000;46:701-706.

19. Englyst HN, Cummings JH. Simplified method for the measurement of total non-starch polysaccharides by gas-liquid chromatography of constituent sugars as alditol acetates. Analyst 1984; 109:937-942.

20. Williams S, ed. AOAC official methods of analysis. 14th ed. Arlington, VA: AOAC, 1984.

21. Jeppesen PB, Mortensen PB. The influence of a preserved colon on the absorption of medium chain fat in patients with small bowel resection. Gut 1998;43:478-483.

22. Jeppesen PB, Staun M, Tjellesen L, Mortensen PB. Effect of intravenous ranitidine and omeprazole on intestinal absorption of water, sodium, and macronutrients in patients with intestinal resection. Gut 1998;43:763-769.

23. Southgate DA, Durnin JV. Calorie conversion factors. An experimental reassessment of the factors used in the calculation of the energy value of human diets. Br J Nutr 1970;24:517-535.

24. Malmud LS, Fisher RS, Knight LC, Rock E. Scintigraphic evaluation of gastric emptying. Semin Nucl Med 1982;12:116-125.

25. Madsen JL, Jensen M. Gastrointestinal transit of technetium99m-labeled cellulose fiber and indium-111-labeled plastic particles. J Nucl Med 1989;30:402-406.

26. Jeppesen PB, Langholz E, Mortensen PB. Quality of life in patients receiving home parenteral nutrition. Gut 1999;44:844852.

27. Jeppesen PB, Staun M, Mortensen PB. Adult patients receiving home parenteral nutrition in Denmark from 1991 to 1996: who will benefit from intestinal transplantation? Scand J Gastroenterol 1998;33:839-846.

28. O'Keefe SJ, Burnes JU, Thompson RL. Recurrent sepsis in home parenteral nutrition patients: an analysis of risk factors. JPEN J Parenter Enteral Nutr 1994;18:256-263.

29. Beers TR, Burnes J, Fleming CR. Superior vena caval obstruction in patients with gut failure receiving home parenteral nutrition. JPEN J Parenter Enteral Nutr 1990;14:474-479.

30. Bowyer BA, Fleming CR, Ludwig J, Petz J, McGill DB. Does longterm home parenteral nutrition in adult patients cause chronic liver disease? JPEN J Parenter Enteral Nutr 1985;9:11-17.

31. Byrne TA, Persinger RL, Young LS, Ziegler TR, Wilmore DW. A new treatment for patients with short-bowel syndrome. Growth hormone, glutamine, and a modified diet. Ann Surg 1995;222:243254.

32. Byrne TA, Morrissey TB, Nattakom TV, Ziegler TR, Wilmore DW. Growth hormone, glutamine, and a modified diet enhance nutrient absorption in patients with severe short bowel syndrome. JPEN J Parenter Enteral Nutr 1995;19:296-302.

33. Scolapio JS, Camilleri M, Fleming CR, Oenning LV, Burton DD, Sebo TJ, Batts KP, Kelly DG. Effect of growth hormone, glutamine, and diet on adaptation in short-bowel syndrome: a randomized, controlled study. Gastroenterology 1997;113:10741081.

34. Szkudlarek J, Jeppesen PB, Mortensen PB. Effect of high dose growth hormone with glutamine and no change in diet on intestinal absorption in short bowel patients: a randomised, double blind, crossover, placebo controlled study. Gut 2000;47:199 205.

35. Ellegard L, Bosaeus I, Nordgren S, Bengtsson BA. Low-dose recombinant human growth hormone increases body weight and lean body mass in patients with short bowel syndrome. Ann Surg 1997;225:88-96.

36. Rubin DC. Nutrient regulation of intestinal growth and adaptation: role of glucagon-like peptide 2 and the enteroendocrine cell (editorial). Gastroenterology 1999;117:261-263.

37. Nightingale JM. Short bowel, short answer? Gut 1999;45:478479.

38. Forbes GB, Bruining GJ. Urinary creatinine excretion and lean body mass. Am J Clin Nutr 1976;29:1359-1366.

39. Nordgaard I, Hansen BS, Mortensen PB. Colon as a digestive organ in patients with short bowel. Lancet 1994;343:373-376.

40. Scolapio JS. Effect of growth hormone, glutamine, and diet on body composition in short bowel syndrome: a randomized, controlled study. JPEN J Parenter Enteral Nutr 1999;23:309-313.

41. Jeppesen PB, Szkudlarek J, Høy C-E, Mortensen PB. Effect of high dose growth hormone and glutamine on body composition, urine creatinine excretion, fatty acid absorption, and essential fatty acids status in short bowel patients. Scand J Gastroenterol 2001;36:48-54.

Received April 23, 2000. Accepted October 11, 2000.

Address requests for reprints to: Palle Bekker Jeppesen, MD., Ph.D., Department of Medicine CA-2121, Rigshospitalet, Blegdamsvej 9, DK2100 Copenhagen, Denmark. e-mail: Bekker@dadlnet.dk; fax: (45) 35452913.

Supported financially by the European Society of Parenteral and Enteral Nutrition Scientific Committee, the Danish Colitis-Crohn Association, Mimi \& Victor Larsens Foundation, Løvens Research Foundation, Dr. Sofus Carl Emil Friis \& Hustru Olga Doris Friis Foundation, and the Ferring A/S Gastro Prize 2000.

The authors thank Jette Christiansen, Dorte Christensen, Bodil Petersen, Hardi Hansen, and Jan Borg Rasmussen for technical assistance. 